\title{
ZONEAMENTO GEOAMBIENTAL DA REGIÃO DO ALTO-MÉDIO RIO PARAÍBA DO SUL E A CARTA DE APTIDÃO FÍSICA PARA A IMPLANTAÇÃO DE OBRAS VIÁRIAS
}

\author{
TOMOYUKI OHARA ${ }^{1}$, JAIRO ROBERTO JIMÉNEZ-RUEDA ${ }^{2}$, \\ JUÉRCIO TAVARES DE MATTOS ${ }^{3} \&$ NORTON ROBERTO CAETANO ${ }^{4}$
}

\begin{abstract}
GEOENVIRONMENTAL ZONES ON THE UPPER-MIDDLE PARAÍBA DO SUL RIVER REGION AND THE PHYSICAL CHARACTERISTICS MAP IN SUPPORT OF HIGHWAY PLANNING This study describes the procedure used to identify zones considered to be homogeneous on the basis of the physical characteristics of the terrain interpreted on Landsat TM images. The study was carried out on the upper-middle Paraíba do Sul river region, State of São Paulo, Brazil, and took into account the main characteristics of the physical environment (geology, physical geography and soils). The study took into account data from laboratory analysis of soils and rocks in reference to their physical, chemical and mineralogical characteristics of samples from soil profiles, as well as edaphoclimatic information and morphostructural anomalies. The geoenvironmental zones present the technical evaluations of water resources (surface and underground), land use, regional planning, environmental issues, etc. From these informations about geoenvironmental zones, was carried out the methodology of values ponderation, using SIG through the Fuzzy technique and the Analytical Hierarchy Process - AHP. The results are presented as a map of physical characteristics as support for highway planning.
\end{abstract}

Keywords: Remote Sensing, Integrated Analysis of Physical Environment, Geoenvironmental Zones, Geographical Information System, Physical Characteristics Map for Highway Planning, Upper-Middle Paraíba do Sul River Region

Resumo Este artigo apresenta os procedimentos e resultados da análise integrada do meio físico, para subsidiar o planejamento territorial visando múltiplos usos, como obras de engenharia, estudos de recursos hídricos (superficiais e subterrâneos), uso agrícola direcionado, planejamento territorial urbano, proteção ambiental, aterros sanitários para efluentes líquidos e sólidos. A área estudada situa-se na região do alto-médio rio Paraíba do Sul, Estado de São Paulo. A análise do meio físico abrange as principais características fisiográficas, litológicas, unidades e coberturas de alteração intempérica e solos, inclusive análises laboratoriais de solos e rochas coletados em perfis de alteração, associados com informações edafoclimáticas e morfoestruturais, e integradas em zonas e subzonas geoambientais. A partir das informações sobre o zoneamento geoambiental da área foi aplicada a metodologia de ponderação de valores nas informações temáticas utilizando o sistema de informação geográfica (SIG), com o uso da técnica Fuzzy e de álgebra de mapas por operação matemática Analytical Hierarchy Process - AHP. Os resultados são apresentados na Carta de Aptidão Física, com as informações sobre o meio físico para avaliar áreas potenciais para a implantação de obras viárias.

Palavras-chaves: Sensoriamento Remoto, Análise Integrada do Meio Físico, Zoneamento Geoambiental, Sistema de Informação Geográfica, Carta de Aptidão Física para Obras Viárias, Região do Alto-Médio Rio Paraíba do Sul

INTRODUÇÃO Extensas regiões do território brasileiro estão atualmente sob a influência de climas tropical e subtropical, os quais apresentam índices de temperatura e pluviometria elevados, favorecendo a decomposição das rochas e o desenvolvimento de espessos mantos de alteração em diferentes estágios pedogênicos, aqui designados como coberturas de alteração intempérica.

As coberturas de alteração intempérica podem ser entendidas como o resultado da interação de processos exógenos e endógenos na formação de solos. Os processos exógenos provocados fundamentalmente pela interação dos elementos do clima, pela radiação/energia solar, temperatura, umidade relativa, precipitação, vento e gelo são os responsáveis pela geração das paisa- gens arídicas/desérticas, pluviais e/ou fluviais, como também as marinhas, dunares (desérticas ou litorâneas) e glaciares. Já os processos endógenos referem-se à geração de rochas, vulcanismo e deformações tectônicas que vem atuando/interatuando durante um determinado tempo e, portanto, originando diferentes formas de relevo. Estas interações entre processos endógenos e exógenos motivam diferentes adições, subtrações, transformações e translocações, dentro e fora dos maciços rochosos, deixando marcas ou registros caracterizados como VAI (volumes de alteração intempérica), UAI (unidades de alteração intempérica), e que definem os tipos/classes/ordens taxonômicos dos solos, associados a processos específicos denominados aqui como CAI (cober-

1- INPE - Instituto Nacional de Pesquisas Espaciais. Caixa Postal 515, CEP 12.245-970, São José dos Campos, SP, ohara@ltid.inpe.br, Fax (12) 39456488 .

2 - Instituto de Geociências e Ciências Exatas da UNESP de Rio Claro. Caixa Postal 178, CEP 13.506-900, Rio Claro, SP, jairorjr@rc.unesp.br

3 - Escola de Engenharia da UNESP de Guaratinguetá. Caixa Postal 205, CEP 12.500-000, Guaratinguetá, SP, juercio@feg.unesp.br

4 - Pós-Graduação em Geociências e Meio Ambiente do IGCE/UNESP, Rio Claro. Caixa Postal 178, CEP 13.506-900, Rio Claro, SP, nortonrc@rc.unesp.br 
turas de alteração intempérica). As propriedades geopedológicas fundamentais (cor, estrutura, consistência, densidade e limites entre horizontes) associadas às suas características (espessura, capacidade de retenção d'água e profundidade radicular) definem os volumes de intemperismo.

O estudo das CAIs é essencial na avaliação integrada de dados do meio físico que vizem zoneamento geoambiental. O zoneamento, por sua vez, tem por finalidade a obtenção do mapa de zonas e subzonas geoambientais, o qual retrata as informações do meio físico para a definição e priorização das diversas aplicações na geologia de planejamento da região alto-médio do rio Paraíba do Sul.

A partir de informações temáticas do zoneamento geoambiental do alto-médio rio Paraíba do Sul aplicou-se a metodologia de ponderação de valores das informações temáticas, utilizando o sistema de informação geográfica (SIG) pela técnica Fuzzy (BonhamCarter 1994) e de álgebra de mapas por operação matemática Analytical Hierarchy Process - AHP (Saaty 1992). Os resultados são apresentados na Carta de Aptidão Física (Caetano 2002, Caetano et al. 2002), com informações relacionadas ao meio para avaliar as áreas potenciais para implantação de obras viárias.

ÁREA DE ESTUDO Zoneamento geoambiental Aárea de estudo do zoneamento geoambiental tem forma de paralelogramo, correspondente à cena da imagem-quadrante TM/Landsat (quadrante $\mathrm{W}$, ponto 76 , órbita 218), com datas de passagem do satélite em 17 de julho de 1987 e 28 de julho de 1991 . A passagem mais recente tem manchas de nuvens na região de São José dos Campos e Caçapava e foi utilizada para atualizar feições não identificadas na cena de 1987. Essa foi a melhor imagem TM/Landsat na época do início desta pesquisa, tanto na ausência de nuvens como nas condições adequadas de ângulos de elevação e azimute solar.

Os limites da área correspondem, aproximadamente, às coordenadas de $22^{\circ} 35^{\prime}$ a $23^{\circ} 35^{\prime} \mathrm{Se} 44^{\circ} 50^{\prime}$ a $45^{\circ} 55^{\prime} \mathrm{W}$, perfazendo aproximadamente $9.000 \mathrm{~km}^{2}$ (Fig. 1) e abrange partes das serras da Mantiqueira e do Mar e inclui a região litorânea e a bacia do altomédio rio Paraíba do Sul.

Devido às diferenças de altitude na área do alto-médio rio Paraíba do Sul, desde $2.401 \mathrm{~m}$ no pico dos Marins (a nordeste da cidade de Piquete na serra da Mantiqueira) até o nível do mar, os tipos climáticos são marcantes e importantes influenciadores na alteração intempérica e no modelado do relevo da região desde o Holoceno.

No presente estudo adotou-se a classificação do clima baseado na efetividade da precipitação (Jiménez-Rueda et al. 1989), na qual o índice de umidade do clima é obtido por cálculo que leva em conta o total de chuvas, as temperaturas e sua altimetria. Segundo este critério, os tipos climáticos da região leste do Estado de São Paulo se caracterizam (Fig. 2) como úmido ( $\mathrm{Ccw}$ e Ccr), muito úmido (Bcr) e superúmido (Adr).

O clima úmido é representado por dois tipos que diferem principalmente pela variação de cotas. $\mathrm{O}$ tipo $\mathrm{Ccw}$ ocorre no vale do rio Paraíba do Sul e ocupa cotas entre 500 e 800 m, e é caracterizado por clima úmido sem estiagem e subtropical em relação ao aspecto térmico de $18 \mathrm{a} 22^{\circ} \mathrm{C}$. O segundo tipo (Ccr) corresponde às regiões com cotas entre 800 e $1.000 \mathrm{~m}$ e é definido por clima úmido com estiagem no inverno e também pelo aspecto térmico subtropical.

O tipo climático Bcr classificado como muito úmido com aspecto térmico subtropical a temperado, ocupa cotas entre 1.000 e 1.200 $\mathrm{m}$, situa-se na zona transicional entre a prémontana e montana e ocorre ao longo das vertentes das serras do Mar e da Mantiqueira.
O clima superúmido, representado pelo tipo Adr, é temperado de até $16^{\circ} \mathrm{C}$ e ocorre na região com altitudes superiores a $1.300 \mathrm{~m}$.

Os resultados da influência do clima no desenvolvimento e manejo dos solos foram avaliados por Jiménez-Rueda et al. (1989), que levou em conta a temperatura e a capacidade de armazenamento de água ou a influência do período de seca na seçãocontrole do solo, de acordo com o Soil Taxonomy (USDA 1975) e em função de dados de precipitação/evaporação, estabelecendo dessa forma quatro regimes de umidade edafoclimáticos (Fig. 3):

a) regime áquico - distribuído na região do vale atual/recente do rio Paraíba do Sul;

b) regime ústico - na região do paleovale do rio Paraíba do Sul e partes baixas das vertentes das serras da Mantiqueira e do Mar;

c) regime údico - distribuído na região de zona prémontana;

d) regime perúdico - associado à região de zona montana.

Carta de aptidão física A Carta de Aptidão Física mostra os resultados da aplicação do Sensoriamento Remoto e Sistema de Informação Geográfica (SIG) na caracterização do meio físico, como subsídio à fase de reconhecimento no projeto de construção de uma rodovia. Para estudo de caso adotou-se a rodovia Governador Carvalho Pinto, na área teste entre $22^{\circ} 45^{\prime}$ a $23^{\circ} 10^{\prime} \mathrm{Se} 45^{\circ} 15^{\prime}$ a $45^{\circ} 40^{\prime} \mathrm{W}$ e abrange parte dos municípios de Caçapava, Taubaté, Pindamonhangaba, Campos do Jordão, São Luís do Paraitinga, Roseira e Aparecida do Norte (Fig. 4).

Segundo Vedovello (2000), a análise dos condicionantes geológicos, geotécnicos e ambientais no estudo das potencialidades da área resulta em uma carta de aptidão física.

No uso do solo destaca-se a ocupação humana, com o crescimento de diversos centros urbanos ao longo da via Dutra (Kurkdjian et al. 1992), além de pastagens, mata ou capoeira e também reflorestamento, vegetação residual ou em recuperação, culturas anuais ou perenes, corpos d'água e campo natural.

\section{SISTEMÁTICA UTILIZADA Zoneamentogeoambiental O} zoneamento geoambiental foi realizado com abordagem metodológica que investigou e caracterizou os atributos espaciais em imagens orbitais, com emprego de técnicas de interpretação visual de dados. A seqüência operacional do estudo foi executada conforme o diagrama de fluxo de trabalho (Fig. 5).

Os limites das zonas geoambientais são regiões geralmente associadas a contatos litológicos e eventualmente, a limites erosivos e descontinuidades estruturais (discordâncias e falhas). Essas zonas foram subdivididas em função de variáveis e/ou de deformações tectônicas que condicionam as formas de relevo e seus respectivos graus de alteração intempérica. As variáveis consideradas foram os tipos de paisagens ou unidades fisiográficas, graus de dissecação do relevo, diferenças edafoclimáticas, anomalias morfoestruturais e morfometria, além dos processos específicos de alteração intempérica ou do tipo de colóide intempérico predominante (paragênese de colóides), resultando no mapa de zonas e subzonas geoambientais da região do alto-médio rio Paraíba do Sul (Ohara 1995, Ohara et al. 1997a, 1997b).

O zoneamento geoambiental deve ter como meta, o fornecimento de subsídios técnicos para orientar e elucidar a tomada de decisões na implementação de alternativas de desenvolvimento regional compatíveis com a sustentabilidade e vulnerabilidade dos sistemas ambientais.

Com a compartimentação realizada foi necessário efetuar análises de homogeneidade e de similaridade. A análise de homogeneidade consistiu em verificar a existência de heterogeneidades 


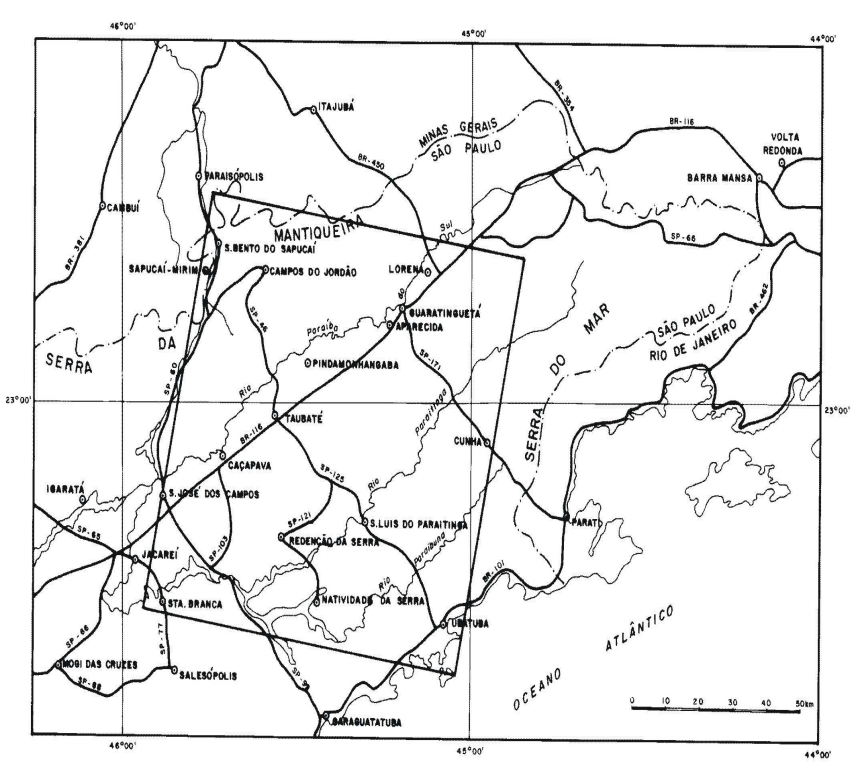

Figura 1 - A área do polígono estudado no zoneamento geoambiental e as principais cidades e rodovias.

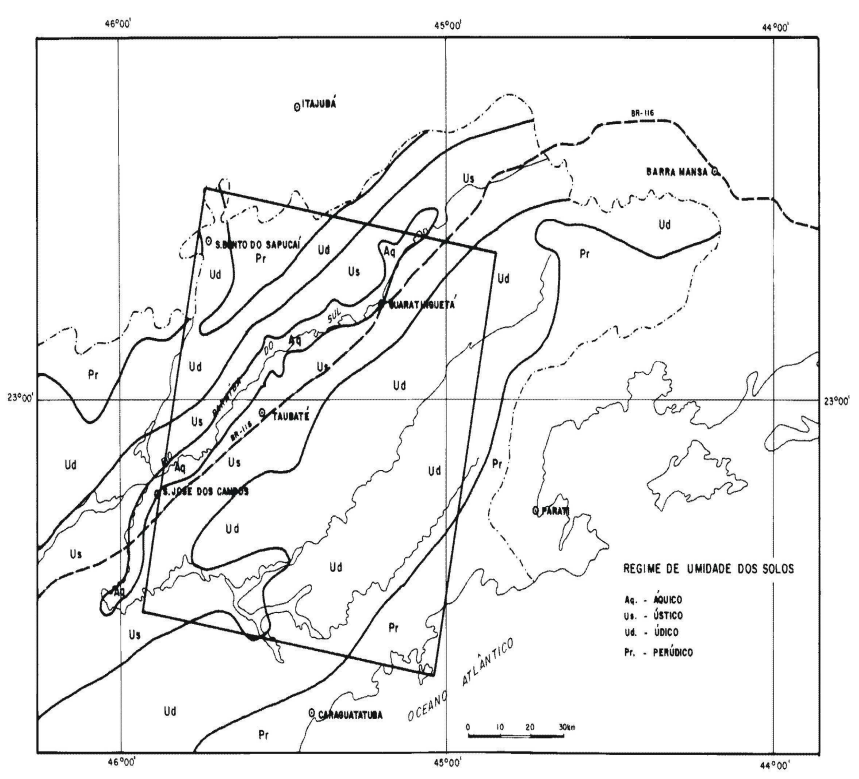

Figura 3 - Distribuição dos regimes de umidade dos solos (Jiménez-Rueda et al. 1989).

internas, nas unidades que justifiquem sua subdivisão por meio de novos limites. A análise de similaridade verifica a existência de unidades com características e/ou propriedades semelhantes, que devem ser classificadas sob as mesmas denominações. No caso de unidades adjacentes, identificadas como similares, o limite entre elas foi removido.

Para complementar a confiabilidade na compartimentação foram realizados trabalhos de campo, essenciais para definir as características fotogeológicas e conferir hipóteses levantadas na fase de

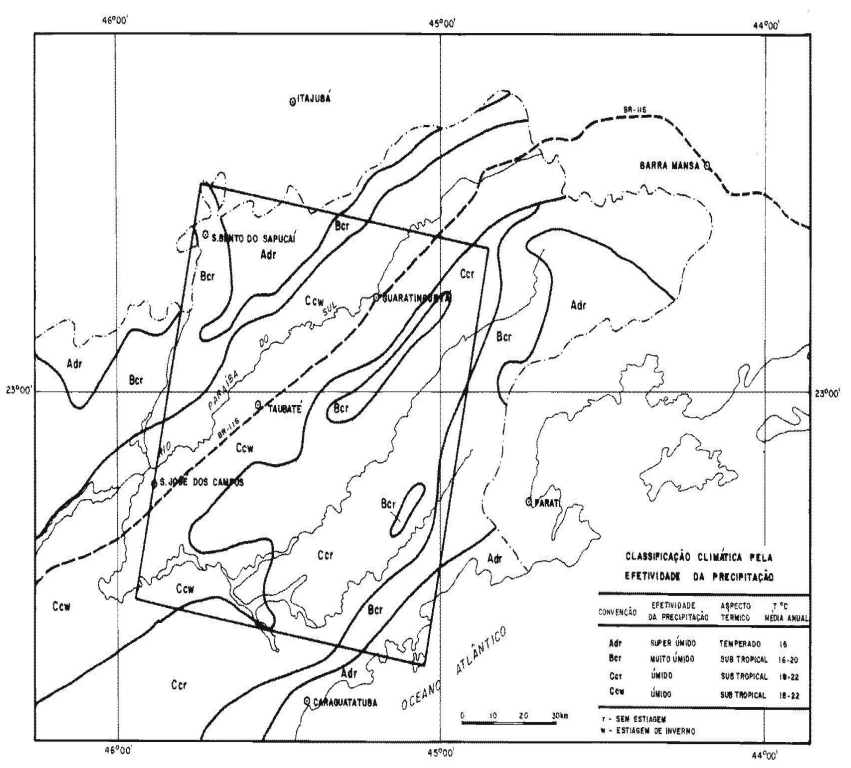

Figura 2 - Os tipos climáticos considerando-se a efetividade da precipitação (Jiménez-Rueda et al. 1989).

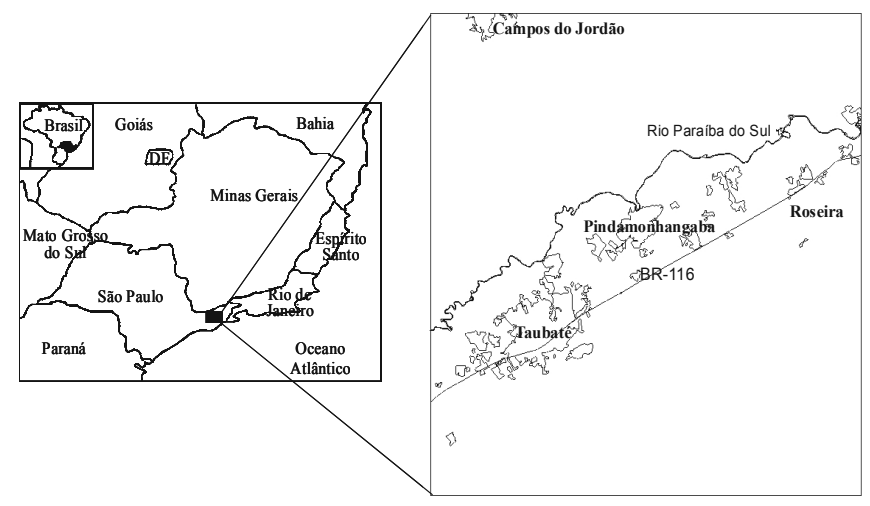

Figura 4 - Localização da área-teste da Carta de Aptidão Física.

fotointerpretação. Por outro lado, podem ocorrer, também, novas dúvidas ou incertezas, devendo-se então recorrer novamente à fotointerpretação e novos trabalhos de campo até esclarecer todas as informações duvidosas.

As campanhas de campo na região do alto-médio rio Paraíba do Sul foram realizadas em 2 fases, uma de reconhecimento e outra detalhada, com coleta de amostras em perfis de alteração intempérica e rochas subjacentes.

A primeira fase de campo teve caráter de reconhecimento, com a finalidade de avaliação regional das principais características fisiográficas, litológicas e estruturais da área de estudo, e foi executada em três campanhas durante julho e agosto de 1992, percorrendo-se, principalmente, as rodovias estaduais e federais da área. A segunda fase foi executada em sete campanhas durante agosto, setembro, outubro e novembro de 1993 . Foram percorridas praticamente todas as rodovias e estradas da área, em locais predeterminados e escolhidos segundo as dificuldades e/ou incertezas 


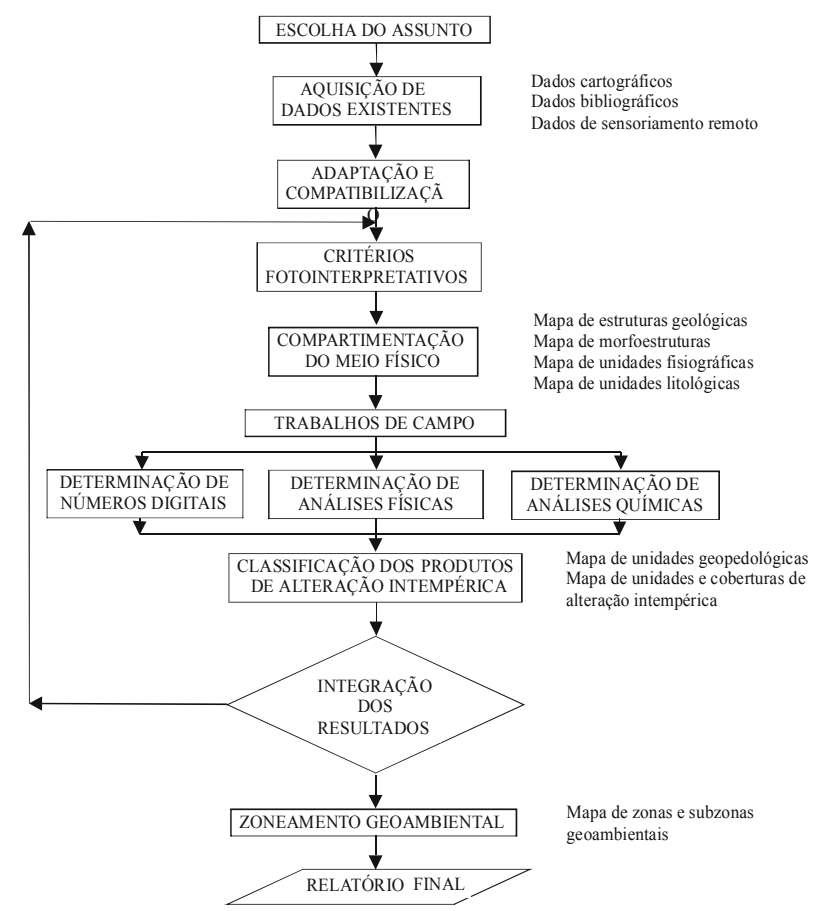

Figura 5 - Diagrama de fluxo de trabalho utilizado no zoneamento geoambiental.

verificadas nos mapas fotointerpretados preliminares. Nessa fase executou-se cerca de $600 \mathrm{~km}$ de perfis e 150 pontos de observação, com descrição detalhada da situação fisiográfica, constituição litológica e estrutural, tipo de uso da terra, e amostragem de perfis de alteração intempérica e rochas subjacentes.

As amostras coletadas foram preparadas para análises físicas e químicas, de elementos totais e elementos trocáveis, e realizadas nos laboratórios do Instituto de Geociências e Ciências Exatas da UNESP de Rio Claro (UNESP/IGCE).

Carta de aptidão física $\mathrm{O}$ método usado para obter a carta de aptidão física baseou-se na análise dos fatores geológicos e geotécnicos condicionantes do meio físico (solo, relevo, rocha e fraturas) em conjunto com os de interesse rodoviário (declividade, uso e cobertura da terra e áreas de uso restrito) para mapear a potencialidade da área na implantação de rodovias, em nível de reconhecimento (Caetano 2002).

As informações do meio físico obtidas do zoneamento geoambiental de Ohara (1995) foram reinterpretadas, tendo por base cartográfica as imagens dos satélites ETM+/Landsat-7 (obtida em agosto de 1999) e HRVIR/Spot-4 (obtida em abril de 1995) na projeção UTM(Universal Transversa de Mercator), datum Córrego Alegre - MG. Todos os dados foram armazenados, processados, analisados e cartografados em ambiente SIG e os resultados apresentados na Carta de Aptidão Física. A sistemática metodológica consta da figura 6 .

A partir das informações obtidas no estudo de zoneamento geoambiental, desenvolveu-se uma sistemática de ponderação de valores das informações temáticas utilizando o SIG com a técnica Fuzzy e da "álgebra de mapas" por operação matemática Analytical Hierarchy Process (AHP), que permite obter a média ponderada dos planos de informação, podendo-se atribuir diferentes pesos a

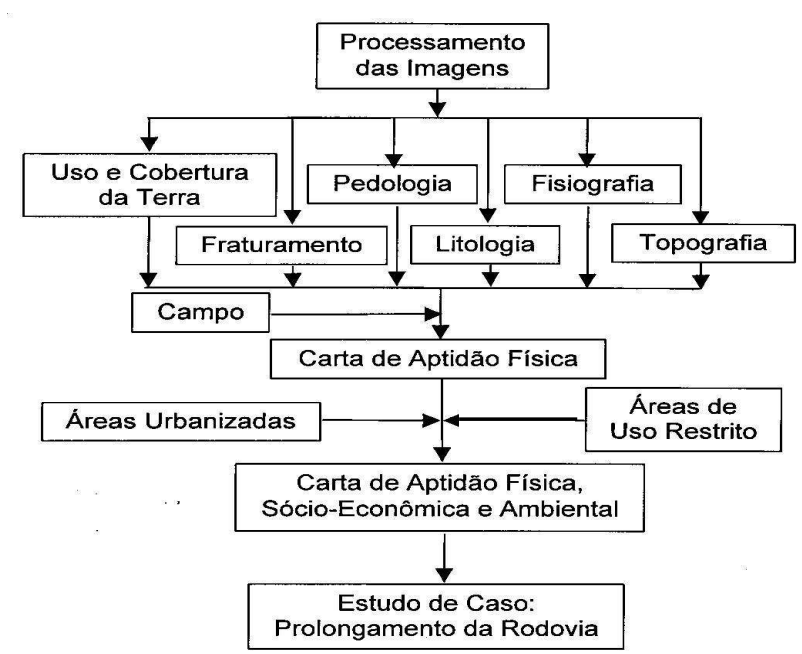

Figura 6 - Diagrama de Fluxo de Trabalho utilizado na Carta de Aptidão Física, Sócio-Econômica e Ambiental.

cada um (Saaty 1992).

O operador lógico Fuzzy é uma técnica computacional de integração ou de modelamento em dados numéricos do meio físico realizado em SIG (Bonham-Carter 1994). No presente trabalho utilizou-se da lógica Fuzzy na modelamento dos dados de densidade de lineamentos estruturais e densidade de cruzamentos de lineamentos, com o intuito de normalizá-los em escala de 0 a 10. Essa técnica foi necessária para a operação matemática no AHP juntamente com os dados de uso e cobertura da terra, pedológico, litológico, fisiográfico e declividade. Com essa sistematização elaborou-se uma Carta de Aptidão Física (Caetano 2002, Caetano et al. 2002) com informações integradas do meio físico, a qual permitiu avaliar as áreas potenciais para a implantação de obras viárias.

DISCUSSÃO DOS RESULTADOS O mapa de zonas e subzonas geoambientais (Fig. 7) apresenta 8 zonas e 47 subzonas geoambientais intimamente relacionadas com as características do meio físico (Tabelas 1, 2, 3, 4 e 5), de cuja análise é possível fazer as seguintes considerações:

a) a latossolização domina nas regiões físiográficas representadas por planaltos desde muito alto (na zona ZGMC e na subzona ZGXG2), alto (nas subzonas SGTM1, SGTD1, SGNG2, SGNM, SGND1, ZGXG1, SMGX e na zona ZGEC) até médio (nas subzonas SBGE, SBGF1, SBGF2, SGNG1, SGNB1, SMGH1 eSMGH2);

b) nas regiões fisiográficas de planaltos baixo e muito baixo, domina a podzolização (nas subzonas SBGF4, SGTM3, SGTD2, SGTD3, SGTP2, SGTX, SGNX2, SGNB2, SGND2, SGNZ2, SGNH2, ZGXG3 e SMGB), com localizadas áreas de latossolização na subzona granitóides migmatíticos 2 (SGTM2);

c) nas regiões do Vale do Paraíba (subzonas SSDF, SSDL1, SSDL2 e SSDL3) e Costeira (subzonas SSDM, SGTX, SGNH1 e SGNH2) não ocorre latossolização, mas predomina a podzolização com localizada cambissolização;

d) cambissolização e/ou regolitização ocorre somente na subzona granitos gnáissico finos (SGTX), restrita à região Costeira e é representada por planalto muito baixo, fortemente dissecado e com feições texturais/estruturais de escarpas festonadas;

e) as regiões da Serra da Mantiqueira e do Paraitinga-Paraibuna são dominadas por edafoclimas údico e perúdico, respectivamen- 
te muito úmido e superúmido, que favorecem a permanência mais prolongada da água nos solos, dessa forma contribuindo com a alteração intempérica durante a maior parte do ano.

Na região da Serra da Mantiqueira também há a influência do edafoclima ústico, principalmente nas áreas de planalto baixo, onde a estiagem de inverno favorece a deficiência hídrica nos solos da região. Isto é corroborado pela presença de Cambissolos latossolizados (EMBRAPA/CNPS 1999), com morfoestruturas negativas e positivas em biotita gnaisses e xistos (subzona SGNX2). Outros solos do edafoclima ústico são Argissolos Vermelhos (subzona SGND2) e Latossolo Vermelho Amarelo (subzona SGNX1);

f) a região do Vale do Paraíba é caracterizada pelos edafoclimas ústico e áquico que favorecem a formação de Cambissolo, Latossolos Vermelhos e Argissolos Vermelhos, resultantes da decomposição de sedimentos flúvio-lacustres e característicos de unidades mono/bissialíticas;

g) na região entre a cidade de Paraibuna e a represa do ParaitingaParaibuna, ocorre uma falha normal NNW, com o bloco ocidental (subzona SGTM3) abatido em relação ao bloco oriental (subzona SGTM4) e, com mergulho aparente SSw, inverso do caso anterior.

As linhas de formas (contornos estruturais não-cotados) do bloco ocidental (subzona SGTM3) conforma diversas morfoestruturas negativas fechadas e parcialmente fechadas, as quais favorecem o ambiente redutor e de hidrólise parcial (JiménezRueda et al. 1993), atestado pela presença de Cambissolo latossolizado e Argissolos Vermelho Amarelo.

Outro fato interessante dessa região é a associação inversa das CAIs com esses solos, visto que o Cambissolo latossolizado foi classificado como uma cobertura latossólica e com UAI alítica, enquanto o Argissolo Vermelho Amarelo/Vermelho como cobertura podzólica-cambissólica com UAI bissialítica. Essa associção inversa entre a classificação de solos com as correspondentes unidades e coberturas de alteração intempérica sugerem uma clara retomada da pedogênese após o falhamento;

h) o bloco central que se relaciona com os dois blocos abatidos nas suas extremidades, é estruturalmente elevado e representado por morfoestruturas positivas alongadas no rumo geral E-W. As linhas de formas (contornos estruturais não-cotados) desse bloco assinalam a superposição de outro evento com esforços compressivos ortogonais às morfoestruturas positivas, indicando um redobramento no sentido NS. Nesse bloco é muito evidente a latossolização generalizado, com ocorrência localizada de laterização, principalmente nos locais de altos estruturais e topográficos. Nessas regiões ocorrem intensa lixiviação dos elementos alcalinos e alcalinos terrosos, os quais favorecem a hidrólise total e conseqüente concentração óxi-hidróxidos de metais no perfil de alteração;

i) das 47 subzonas individualizadas na região do alto-médio rio Paraíba do Sul, 22 subzonas (quase a metade) estão afetadas por diversos sistemas de falhas cisalhantes, os quais resultaram em variados graus de intemperismo e, freqüentemente, formas de relevo mais antigas e dissecadas.

A seguir são apresentados as relações das subzonas com os trends de fraturas, juntamente com as informações da fisiografia, litologia, geopedológica, unidades e coberturas de alteração intempérica e de anomalias morfoestruturais (Tabela 1). Na região geográfica da Serra da Mantiqueira 7 subzonas de 3 zonas geoambientais foram afetadas por trends de fratura:

1. na subzona SMGG1 pelas falhas do Ribeirão da Serra (N60E) e Jundiuvira (N65E);

2. as falhas de Piedade (N60E) e Buquira (N60E) afetaram as subzonas SMGG2 e ZGXG3;

3. a subzona ZGXG2 foi afetada pela falha Jundiuvira (N65E) e

Tabela 1 - Relação das zonas e subzonas geoambientais com as unidades litológicas (lito), pedológicas (geopedo), de fisiografias (fisio), de alteração (uai) e coberturas (cai) intempérica, paragênese e anomalias de morfoestruturas (morfo).

\begin{tabular}{|c|c|c|c|c|c|c|c|c|c|c|}
\hline zona & subzona & região & lito & geopedo & fisio & morfo & cai & uai & paragênese & observações \\
\hline \multirow[t]{4}{*}{ ZGSD } & SSDM & $\mathrm{RC}$ & $\mathrm{gm}$ & HPus & pal & \multirow{4}{*}{$\begin{array}{c}\text { baixo } \\
\text { baixo-alto } \\
\text { alto }\end{array}$} & \multirow{4}{*}{ Podz-Camb } & \multirow{4}{*}{ Mono-Bi } & \multirow{4}{*}{ caul-mont } & \\
\hline & SSDF & \multirow[t]{3}{*}{ RVP } & agar & HGHaq & nai & & & & & \\
\hline & SSDL1 & & \multirow[t]{2}{*}{ sfl } & Cus & \multirow[t]{2}{*}{ pei } & & & & & \\
\hline & $\begin{array}{l}\text { SSDL2 } \\
\text { SSDL3 }\end{array}$ & & & $\begin{array}{l}\text { LVeus } \\
\text { PVeus1 }\end{array}$ & & & & & & \\
\hline ZGMC & & RSM & $\mathrm{cm}$ & $\mathrm{CHpr}$ & Pmafdn & alto & \begin{tabular}{|l} 
Latos-Podz \\
\end{tabular} & Mono & caul & \\
\hline \multirow{4}{*}{$\frac{\mathrm{ZGMC}}{\mathrm{ZGBG}}$} & SBGE & & & LVeud2 & Pmfdn & baixo & & Ali-Mono & gibb-caul & \\
\hline & SBGF1 & \multirow[t]{10}{*}{ RPP } & \multirow[t]{3}{*}{ grf } & LVaud4 & Pmmdn & \multirow[t]{3}{*}{ alto-baixo } & \begin{tabular}{|l} 
Latos-Podz \\
\end{tabular} & Mono & caul & \\
\hline & $\frac{\text { SBGG2 }}{\text { SBGF3 }}$ & & & & $\frac{\text { Pmmdo }}{\text { Pbmdn }}$ & & & & & \begin{tabular}{|l} 
Pequena área próxima a Jambeiro \\
Área próxima a Redenção da Serra
\end{tabular} \\
\hline & SBGF4 & & & LVaud3 & $\mathrm{PbFdn}$ & & $\begin{array}{l}\text { Podz-Camb } \\
\end{array}$ & Mono-Bi & caul-mont & Granito Aparecida \\
\hline \multirow[t]{7}{*}{$\overline{\text { ZGGT }}$} & $\begin{array}{l}\text { SGTM1 } \\
\text { SGTM2 }\end{array}$ & & \multirow[t]{3}{*}{ ymp } & Clud2 & $\begin{array}{l}\text { Pamdo } \\
\text { Pbfdn }\end{array}$ & \multirow[t]{2}{*}{ baixo-alto } & Latos & Ali & gibb & \\
\hline & $\frac{\mathrm{SOIN2}}{\mathrm{SGTM} 3}$ & & & PVa/eud & $\begin{array}{l}\text { Pbormdo } \\
\text { Pbmdo }\end{array}$ & & Podz & $\mathrm{Bi}$ & mont & $\begin{array}{l}\text { W de Paraibuna } \\
\text { Paraibuna } \\
\end{array}$ \\
\hline & SGTM4 & & & LVaudl & & alto & \begin{tabular}{|l} 
Latos-Podz \\
\end{tabular} & Mono & caul & Represa \\
\hline & SGTDI & & \multirow[t]{2}{*}{$\mathrm{ydm}$} & PVapr & PaFdo & alto-baixo & Latos & Ali-Mono & gibb-caul & Falha de Natividade da Serra \\
\hline & $\begin{array}{ll}\text { SGTD2 } \\
\text { SGTD23 }\end{array}$ & & & PVaud3 & $\begin{array}{l}\mathrm{Pbfdo} \\
\mathrm{Phfdn}\end{array}$ & baixo & Podz-Camb & $\frac{\mathrm{Mono}-\mathrm{Bi}}{\mathrm{Bi}}$ & caul-mont & $\begin{array}{l}\text { SW de Paraibuna - Falha de Natividade da Serra } \\
\text { Santa Branca }\end{array}$ \\
\hline & $\frac{S_{10}}{\text { SGTP1 }}$ & & ygp & PVeud1 & Pmmdn & alto & \multirow[t]{2}{*}{ Podz-Camb } & \multirow[t]{2}{*}{ Mono-Bi } & \multirow{2}{*}{ caul-mont } & $\begin{array}{l}\text { Panto na região da serra Fria ou dos Forrós } \\
\text { PaFdo }\end{array}$ \\
\hline & SGTP2 & & & PVaud(LVeus) & Pbmdn & \multirow{3}{*}{ baixo-alto } & & & & \\
\hline \multirow{13}{*}{$\overline{\text { ZGGN }}$} & & \multirow{3}{*}{$\frac{\mathrm{RC}}{\mathrm{RPP}}$} & \multirow{2}{*}{$\frac{\mathrm{vgf}}{\operatorname{bgx}}$} & $\frac{\mathrm{Cpr}}{\mathrm{PVaud(LVeus/ud)}}$ & $\frac{P m b F d c}{P m F d o}$ & & & & & \\
\hline & $\begin{array}{l}\mathrm{SUNG1} \\
\mathrm{SGNG} 2 \\
\end{array}$ & & & $\begin{array}{l}\text { PVaud(LVeus/uda) } \\
\text { PVaud4 }\end{array}$ & $\begin{array}{l}\text { Pmimeo } \\
\text { Pamdo }\end{array}$ & & \begin{tabular}{|l} 
Latos-Podz \\
\end{tabular} & $\begin{array}{l}\text { AAl-Mono } \\
\text { Mono }\end{array}$ & $\frac{\text { gibb-caul }}{\text { caul }}$ & $\begin{array}{l}\text { Falha do Quebra Cangalha } \mathrm{e}<\text { amplitude a sw de Rede } \\
\end{array}$ \\
\hline & SGNO & & gng & Clud1 & PmFdo & alto & Podz-Camb & Mono-Bi & caul-mont & \begin{tabular}{|l|l|l|} 
PmFdn de NW de Ubatuba até a serra do Indaiá - Falha do Indaiá \\
\end{tabular} \\
\hline & SGNX1 & RSM & $\mathrm{bx}$ & LVaus & Pbmdn & & Latos-Podz & Mono & caul & Com textura fina \\
\hline & SGNX2 & & & Clus & & baixo-alto & Podz-Camb & Mono-Bi & caul-mont & \begin{tabular}{|l|l|l} 
Com textura fina \\
Falla
\end{tabular} \\
\hline & SGNF & RPP & $\frac{\text { bof }}{\text { bob }}$ & PVeudl & & alto-baixo & Latos-Podz & Mono & & $\begin{array}{l}\text { Falha Alto da Fartura } \\
\text { PmFdo prox rive Paraiting }\end{array}$ \\
\hline & SGNB2 & & & $\begin{array}{l}\text { Lveudl } \\
\text { PVendl }\end{array}$ & PbFdn & baixo-alto & Podz-Camb & Mono-Bi & caul-mont & $\begin{array}{l}\text { Pmffolo próx, rio Paraitinga e extrem. SW - Fallha Alto da Far } \\
\text { "Mar de Morros" - região de Aparecida }\end{array}$ \\
\hline & SGNM & RSM & $\mathrm{gmb}$ & Cud2 & PaFdc & & Latos-Podz & Mono & caul & \\
\hline & SGND1 & & bgn & PVepr & Pamdo & alto-baixo & Latos & Ali-Mono & gibb-caul & imbra e da Água Santa - Fal \\
\hline & SGND2 & & & PVeus 2 & Pbmdn & monoclinal & Podz & Bi & mont & \\
\hline & SGNZZ & RPP & bom & PVeudl & PmFdo & & \begin{tabular}{|l|} 
Podz-Camb \\
\end{tabular} & Mono-Bi & caul-mont & atura - serra do Ouebrac \\
\hline & SGNZ2 & & & PYeud(PVaus) & PbFdo & baixo & Podz & $B \mathrm{Bi}$ & mont & Falha Sern \\
\hline & $\begin{array}{l}\text { SGNH1 } \\
\text { SGNH2 }\end{array}$ & $\overline{\mathrm{RC}}$ & $\mathrm{ch}$ & PVaud1 & $\frac{\text { pel (isialado) }}{\text { Pmbmdn }}$ & alto-baixo & Podz-Camb & Mono-Bi & caul-mont & \\
\hline $7 \mathrm{GEC}$ & & RPP & & LVanrl & Pamdo & alto & & & & Falha de Natividade da Serra \\
\hline ZGXG & & RSM & 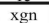 & LVaud2 2 & PaFdn & & \begin{tabular}{|l} 
Latos-Podz \\
\end{tabular} & & & \\
\hline & ZGXG2 & & & LVapr2 & PmaFdo & & Latos & Ali & gibb & Falha Jundiuvira \\
\hline & ZGXG3 & & & Clud3 & Pbmdo & baixo-alto & Podz-Camb & Mono-Bi & caul-mont & Falha do Buquira \\
\hline ZGMG & SMGX & $\mathrm{RPP}$ & mex & Cud1 & PaFdo & baixo & & & & Falha de Santa Rita \\
\hline & & RSM & meg & PVelud & PmFdo & alto & & & & Sul da serra do Palmital: formas escarpadas baixas - Falha do Ribeirão da Serra \\
\hline & SMGG2 & & & PVeud2 & & baixo-alto & Podz & $\mathrm{Bi}$ & mont & 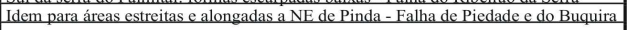 \\
\hline & SMGT & & met & PVaud & Pmmdo & & \begin{tabular}{|l} 
Podz-Camb \\
\end{tabular} & Mono-Bi & caul-mont & \\
\hline & SMGB & RPP & $\mathrm{mgb}$ & PVaud2 & PbFdn & & & & & \\
\hline & $\frac{\mathrm{SMGHL}}{\mathrm{SMGH} 2}$ & RSM & mch & PVaud + Cud & $\begin{array}{l}\text { Pmmdn } \\
\text { Pmmdo }\end{array}$ & & Latos & Ali & gibb & PmEdo - região do Parque Estadual de Campos do Jordão \\
\hline
\end{tabular}


Tabela 2 - Abreviaturas elou siglas utilizadas nas colunas zona e subzona geoambientais da Tabela 1.

\begin{tabular}{|c|c|c|}
\hline ZGSD & & Zona Geoambiental Sedimentos \\
\hline & SSDM & Subzona Sedimentos Marinhos \\
\hline & SSDF & Subzona Sedimentos Fluviais \\
\hline & SSDL1 & Subzona Sedimentos Flúvio-Lacustres-1 \\
\hline & SSDL2 & Subzona Sedimentos Flúvio-Lacustres-2 \\
\hline & SSDL3 & Subzona Sedimentos Flúvio-Lacustres-3 \\
\hline ZGMC & & Zona Geoambiental Metaconglomerados \\
\hline \multirow[t]{6}{*}{ ZGBG } & & Zona Geoambiental Biotita Granitos \\
\hline & SBGE & Subzona Granitos Equigranulares \\
\hline & SBGF1 & Subzona Granitóides Foliados-1 \\
\hline & SBGF2 & Subzona Granitóides Foliados-2 \\
\hline & SBGF3 & Subzona Granitóides Foliados-3 \\
\hline & SBGF4 & Subzona Granitóides Foliados-4 \\
\hline \multirow[t]{11}{*}{ ZGGT } & & Zona Geoambiental Granitóides \\
\hline & SGTM1 & Subzona Granitóides Migmatíticos-1 \\
\hline & SGTM2 & Subzona Granitóides Migmatíticos-2 \\
\hline & SGTM3 & Subzona Granitóides Migmatíticos-3 \\
\hline & SGTM4 & Subzona Granitóides Migmatíticos-4 \\
\hline & SGTD1 & Subzona Granitóides a Duas Micas-1 \\
\hline & SGTD2 & Subzona Granitóides a Duas Micas-2 \\
\hline & SGTD3 & Subzona Granitóides a Duas Micas-3 \\
\hline & SGTP1 & Subzona Granitóides Porfiróides-1 \\
\hline & SGTP2 & Subzona Granitóides Porfiróides- 2 \\
\hline & SGTX & Subzona Granitos Gnáissicos Finos \\
\hline \multirow[t]{16}{*}{ ZGGN } & & Zona Geoambiental Gnaisses \\
\hline & SGNG1 & Subzona Biotita Gnaisses Granitóides e Xistos-1 \\
\hline & SGNG2 & Subzona Biotita Gnaisses Granitóides e Xistos-2 \\
\hline & SGNQ & Subzona Gnaisses e Quartzitos \\
\hline & SGNX1 & Subzona Biotita Gnaisses e Xistos-1 \\
\hline & SGNX2 & Subzona Biotita Gnaisses e Xistos-2 \\
\hline & SGNF & Subzona Biotita Gnaisses Finos \\
\hline & SGNB1 & Subzona Biotita Gnaisses Bandados-1 \\
\hline & SGNB2 & Subzona Biotita Gnaisses Bandados-2 \\
\hline & SGNM & Subzona Gnaisses e Migmatitos Blastomiloníticos \\
\hline & SGND1 & Subzona Biotita Gnaisses Granodioríticos-1 \\
\hline & SGND2 & Subzona Biotita Gnaisses Granodioríticos-2 \\
\hline & SGNZ1 & Subzona Biotita Gnaisses Migmatizados-1 \\
\hline & SGNZ2 & $\begin{array}{l}\text { Subzona Biotita Gnaisses Migmatizados-2 } \\
\end{array}$ \\
\hline & SGNH1 & Subzona Gnaisses com Charnoquitos-1 \\
\hline & SGNH2 & Subzona Gnaisses com Charnoquitos-2 \\
\hline ZGEC & & Zona Geoambiental Ectinitos Síltico Argilosos \\
\hline \multirow[t]{4}{*}{ ZGXG } & & Zona Geoambiental Xistos e Gnaisses \\
\hline & ZGXG1 & Subzona Xistos e Gnaisses-1 \\
\hline & ZGXG2 & Subzona Xistos e Gnaisses-2 \\
\hline & ZGXG3 & Subzona Xistos e Gnaisses-3 \\
\hline \multirow[t]{8}{*}{ ZGMG } & & Zona Geoambiental Migmatitos \\
\hline & SMGX & Subzona Migmatitos Estromatíticos com Paleossoma Xistoso \\
\hline & SMGG1 & Subzona Migmatitos Estromatíticos e Gnaisses-1 \\
\hline & SMGG2 & Subzona Migmatitos Estromatíticos e Gnaisses-2 \\
\hline & SMGT & Subzona Migmatitos Estromatíticos com Neossoma Tonalítico \\
\hline & SMGB & Subzona Migmatitos Estromatíticos ou Gnaisses Bandados \\
\hline & SMGH1 & Subzona Migmatitos Policíclicos Homogêneos com Charnoquitos-1 \\
\hline & SMGH2 & Subzona Migmatitos Policíclicos Homogêneos com Charnoquitos-2 \\
\hline
\end{tabular}

Tabela 4 - Abreviaturas e/ou siglas utilizadas na coluna fisio (unidades fisiográficas) da Tabela 1.

\begin{tabular}{|c|c|c|c|}
\hline \multirow[t]{9}{*}{$\mathrm{P}$ - planalto } & \multirow[t]{5}{*}{ ma-muito alto } & \multirow[t]{3}{*}{$\mathrm{Fd}$ - fortemente dissecado } & 0 - orientado \\
\hline & & & n - não orientado \\
\hline & & & c - escarpado \\
\hline & & \multicolumn{2}{|c|}{ md - moderadamente dissecado } \\
\hline & & \multicolumn{2}{|l|}{ fd - fracamente dissecado } \\
\hline & \multicolumn{3}{|l|}{$\mathrm{a}-$ alto } \\
\hline & \multicolumn{3}{|l|}{$\mathrm{m}$ - médio } \\
\hline & \multicolumn{3}{|l|}{ b - baixo } \\
\hline & \multicolumn{3}{|l|}{$\begin{array}{l}\mathrm{mb}-\text { muito } \\
\text { baixo }\end{array}$} \\
\hline \multirow[t]{3}{*}{ p-planície } & \multirow[t]{2}{*}{ e - erosão } & \multicolumn{2}{|l|}{1 - litơrâneo } \\
\hline & & \multicolumn{2}{|l|}{ i - interplanáltico } \\
\hline & \multicolumn{3}{|l|}{$a-$ acumulação } \\
\hline
\end{tabular}

Tabela 3 - Abreviaturas elou siglas utilizadas na coluna lito (unidades litológicas) da Tabela 1 .

\begin{tabular}{|l|l|}
\hline agar & sedimentos fluviais \\
bx & biotita gnaisses e xistos \\
bgb & biotita gnaisses bandados \\
bgf & biotita gnaisses finos \\
bgm & biotita gnaisses migmatizados \\
bgn & biotita gnaisses granodioríticos \\
bgx & biotita gnaisses granitóides e xistos \\
ch & gnaisses com charnoquitos \\
cm & metaconglomerados \\
gmb & gnaisses e migmatitos blastomiloníticos \\
gnq & gnaisses e quartzitos \\
gre & granitos equigranulares \\
grf & granitóides foliados \\
mch & migmatitos policíclicos homogêneos com charnoquitos \\
meg & migmatitos estromatíticos e gnaisses \\
met & migmatitos estromatíticos com neossoma tonalítico \\
mex & migmatitos estromatíticos com paleossoma xistoso \\
mgb & migmatitos estromatíticos ou gnaisses bandados \\
qm & sedimentos marinhos \\
re & ectinitos síltico-argilosas \\
sfl & sedimentos flúvio-lacustres \\
xgn & xistos e gnaisses \\
$\gamma d m$ & granitóides a duas micas \\
$\gamma g f$ & granitos gnáissicos finos \\
$\gamma g p$ & granitóides porfiróides \\
$\gamma \mathrm{mp}$ & granitóides migmatíticos \\
\hline
\end{tabular}

Tabela 5 - Abreviaturas elou siglas utilizadas nas colunas cai (coberturas de alteração intempérica) e uai (unidades de alteração intempérica), paragênese de colóides e geopedo (unidades geopedológicas) da Tabela 1.

\begin{tabular}{|l|}
\hline cai - cobertura de alteracão intempérica \\
Latos - latossólica \\
Podz - podzólica \\
Camb - cambissólica \\
\hline uai - unidade de alteração intempérica \\
Ali - alítica \\
Mono - monossialítica \\
Bi - bissialítica \\
\hline \multicolumn{1}{c}{ paragênese } \\
Gibb - gibbsita \\
Caul - caulinita \\
Mont - montmorilonita
\end{tabular}

\section{geopedo - solos}

$L V a p r=L V a+p r$

LVa - Latossolo Vermelho Amarelo

pr - regime perúdico

ud - regime údico

us - regime ústico

aq - regime áquico

$\mathrm{PVa}$ - Argissolo Vermelho Amarelo

C - Cambissolo

PVe - Argissolo Vermelho

LVe - Latossolo Vermelho

LVa - Latossolo Vermelho Amarelo

$\mathrm{CH}$ - Cambissolo Húmico

$\mathrm{Cl}$ - Cambissolo latossolizado

$\mathrm{HGH}$ - Neossolo Flúvico Tb gleico

HP - Espodossolo Hidromórfico 


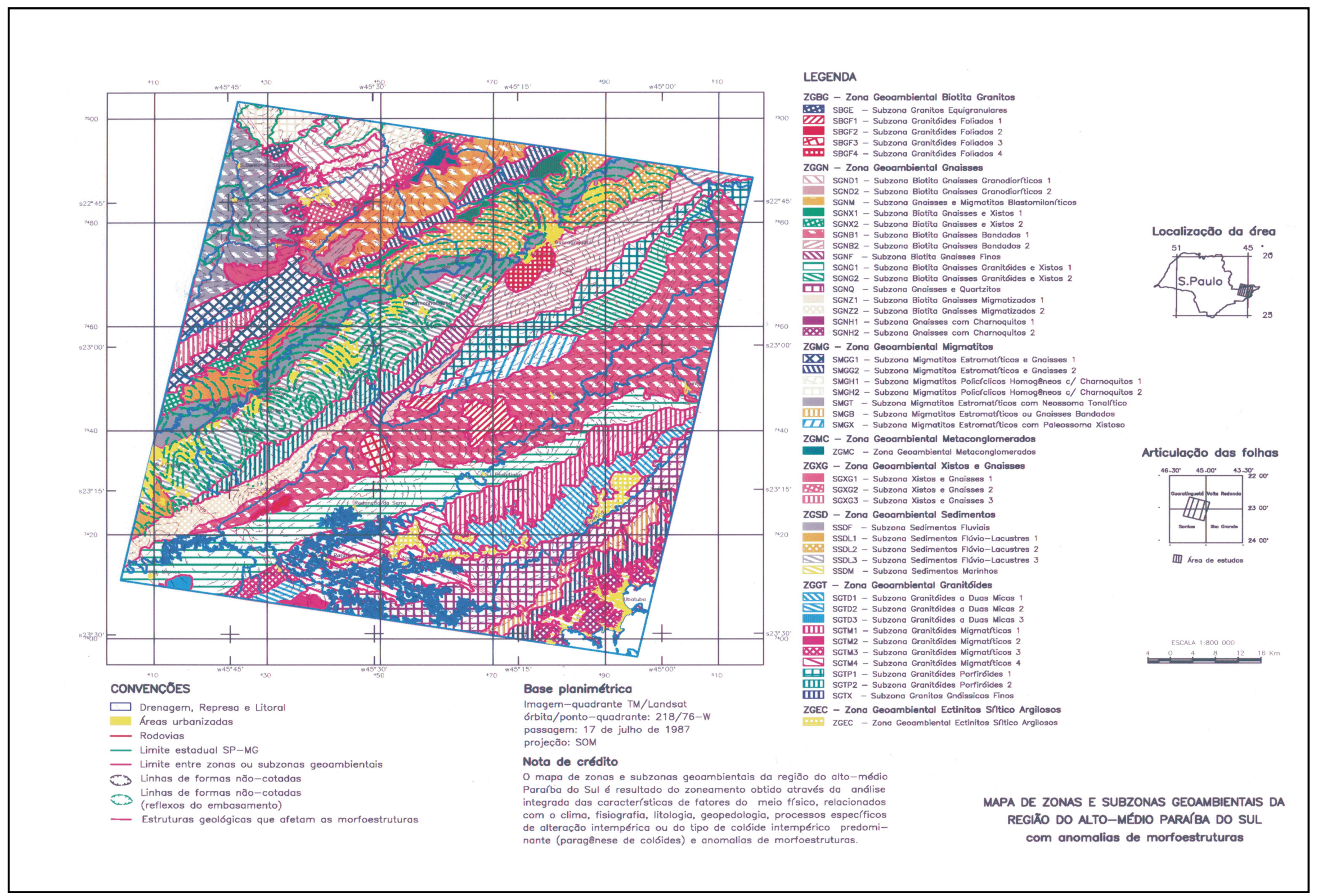


por outros lineamentos, no geral orientadas próximo de EW;

4. a subzona SGND1 foi afetada pela falha do Paiol Grande (N65$70 \mathrm{E}$ ) e outros lineamentos estruturais, também orientados ao redor de EW.

Na região de Paraitinga-Paraibuna ocorrem 15 subzonas afetadas por diversos trends de fraturas, as quais são relacionadas a 5 zonas geoambientais diferentes:

1. a subzona SGNQ se relaciona com a falha do Indaiá (N75E);

2. as falhas de Natividade da Serra (N65-75E) e Cubatão (N70E) afetam a subzona SGTM4;

3. as subzonas SGNG1, SGTM1, SGTM3 se relacionam com as falhas de Taxaquara (N75E) e de Cubatão (N70E);

4. as falhas de Serra do Jambeiro (N60E) e do Rio Comprido (N60E) afetaram a subzona SGNZ2;

5. as subzonas SGNG2 e SMGX se relacionam com a falha de Quebra Cangalha (N55E) e

6. as falhas do Alto da Fartura (N50E) e de Santa Rita (N65-70E) afetam as subzonas SGNB1, SBNF, SGNZ1 e SBGF2.

Aplicações dos Resultados As zonas e subzonas geoambientais determinadas por avaliação integrada das unidades e coberturas de alteração intempérica com as informações edafoclimáticas, fisiográficas, litológicas, geopedológicas e anomalias morfoestruturais forneceram importantes subsídios para a definição de prioridades em diversas aplicações, como por exemplo:

1. Obras de engenharia, tais como implantação de rodovias e grandes edificações são recomendadas em zonas/subzonas com predomínio de morfoestruturas positivas e, moderadamente indicadas em áreas com altos e baixos estruturais. As subzonas mais indicadas são SSDL2 e SSDL3, em função também da intensa expansão urbana e industrial na região do Vale do Paraíba. Essas duas subzonas da região do Vale do Paraíba (RVP) têm substrato litológico de sedimentos flúvio-lacustres (sfl), e são constituídas pela físiografia de planície de erosão interplanáltico (pei), CAI podzólica-cambissólica-latossólica (Podz-Camb-Latos), UAI monossialítica-bissialítica (Mono-Bi) e paragênese de colóides caulinita-montmorilonita (Caul-Mont). A subzona SSDL2 é representada pela unidade geopedológica Latossolo Vermelho com regime de umidade de solos ústico (LVeus) e predomínio de anomalias morfoestruturais positivas (alto). A subzona SSDL3 é representada pela unidade geopedológica Argissolo Vermelho com regime de umidade de solos ústico (PVeus) e predominínio de anomalias morfoestruturais positivas e negativas (alto-baixo);

2. Estudos de recursos hídricos subterrâneos são indicados em áreas com morfoestruturas negativas, onde a circulação d'água é alta e direcionada. Na região do Vale do Paraíba a área mais indicada para obtenção de recursos hídricos subterrâneos é a região entre as cidades de Pindamonhangaba e Roseira, onde há uma ampla morfoestrutura negativa nas subzonas SSDL3 e SSDF. Essas subzonas ocorrem na região do Vale do Paraíba (RVP) e possuem em comum a CAI podzólica-cambissólica-latossólica (Podz-CambLatos), a mesma UAI monossialítica-bissialítica (Mono-Bi) e a mesma paragênese de colóides caulinítica-montmorilonita (CaulMont). As principais características da subzona SSDL3 já foram apresentadas no item anterior. A subzona SSDF que também ocorre na região do Vale do Paraíba (RVP), tem o substrato de sedimentos fluviais (agar) e é representada por planície de acumulação interplanáltico (pai) e por Neossolo Flúvico Tb distrófico gleico com regime de umidade de solos áquico (HGHaq);

3. Uso agrícola direcionado é mais indicado naquelas áreas com alta a média fertilidade atual e potencial. Essa fertilidade está freqüentemente associada a morfoestruturas de baixo estrutural, como é, novamente, o caso da região entre Pindamonhangaba e Roseira. Por coincidência, é nessa região que os técnicos da Secretaria da Agricultura do Estado de São Paulo fazem as experiências agronômicas. As características do meio físico e de paragênese de colóides dessa região foram descritas como caulinitamontmorilonita (Caul-Mont);

4. Planejamento territorial urbano é adequado em áreas com altos estruturais e topográficos, como nas regiões de São José dos Campos (córrego Campestre-Vista Verde), entre Caçapava e Quiririm, Tremembé-Taubaté, nordeste de Pindamonhangaba e noroeste de Guaratinguetá, nas subzonas SSDL3 e SSDL2. As características dessas subzonas foram descritas no primeiro item (obras de engenharia);

5. Proteção ambiental deve estar relacionada, principalmente, com as cabeceiras de bacias hidrográficas, correspondendo normalmente a altos topográficos, como nas serras do Jambeiro (entre as subzonas SGTP2 e SGNZ2) e do Palmital (entre as subzonas SMGG1e ZGXG3), respectivamente a sul e norte de São José dos Campos, Caçapava e Taubaté. As duas primeiras subzonas foram identificadas na região geográfica do Paraitinga-Paraibuna (RPP), e as duas outras na região da Serra da Mantiqueira (RSM);

6. Aterros sanitários para efluentes líquidos e sólidos devem ser indicados em áreas de baixo estrutural e alto topográfico, onde a circulação de líquidos é baixa e direcionada, a percolação é mediana apesar do grande potencial de erosão da área. Na região de São José dos Campos a área mais indicada situa-se a cerca de 2 a $3 \mathrm{~km}$ a sul da Granja Itambi, mais especificamente entre o lago da Maranata e a fazenda Capuava.

Evidentemente, para a implantação de qualquer dessas aplicações nas áreas aqui mencionadas, deve ser executado outros trabalhos com maiores detalhes e direcionados para cada atividade de interesse, inclusive com o envolvimento de outras técnicas afins, tais como trabalhos de sondagens geofísicas para o conhecimento, por exemplo, da espessura do manto de alteração, nível freático, dentre outras.

Carta de Aptidão Física Na Carta de Aptidão Física (Fig. 8 e Tabela 6) testou-se três diferentes traçados para o prolongamento da via Carvalho Pinto. Outros traçados poderiam ter sido propostos e testados, mas o presente trabalho visa, eminentemente, o mapeamento do meio físico, para identificação das melhores áreas à implantação de rodovias (Caetano 2002, Caetano et al. 2002).

As avaliações médias dos três diferentes traçados foram calculadas pela seguinte equação:

$\mathrm{Av}=\left(0 * \mathrm{~N}_{\mathrm{AU}}+0 * \mathrm{~N}_{\mathrm{AUR}}+0 * \mathrm{~N}_{\mathrm{I}}+3,33 * \mathrm{~N}_{\mathrm{D}}+6,66 * \mathrm{~N}_{\mathrm{R}}+10 * \mathrm{~N}_{\mathrm{F}}\right) / \Sigma \mathrm{N}_{\mathrm{i}}$ Onde $\mathrm{Av} \stackrel{\mathrm{AU}}{=}$ avaliação do traçado, $\mathrm{N}_{\mathrm{DU}}=$ número de píxels do traçado inseridos em áreas urbanas, $\mathrm{N}_{\mathrm{AUR}}=$ número de píxels do traçado em áreas de uso restrito, $\mathrm{N}_{\mathrm{I}=}$ número de píxels na classe de aptidão física imprópria, $\mathrm{N}_{\mathrm{D}}=$ número de píxels na classe de aptidão física desfavorável, $\mathrm{N}_{\mathrm{R}}=$ número de píxels na classe de aptidão física regular, $\mathrm{N}_{\mathrm{F}}=$ número de píxels na classe de aptidão física favorável e $\mathrm{N}_{\mathrm{i}}$ = número total de pixels do traçado em questão contado pela operação "tabulação cruzada".

Os pixels de cada traçado, quando em áreas favoráveis, receberam avaliação 10, os inseridos em áreas regulares avaliação 6,66, os de áreas desfavoráveis 3,33 e os de áreas impróprias, urbanizadas ou de uso restrito receberam avaliação 0 .

Tendo-se calculado as avaliações médias para cada traçado, com a equação acima, observou-se o desempenho de cada alternativa e realizou-se uma comparação entre as avaliações médias 
de cada traçado (Tabela 7).

O traçado 1, em comparação com os outros, percorre áreas mais desfavoráveis para implantação de rodovias. A sua avaliação média é a mais baixa entre os traçados propostos $(\mathrm{Av}-1=8,39)$. Cerca de $33,1 \%$ de seu traçado estão inseridos em áreas não favoráveis para a implantação de rodovias. Apesar de ser a avaliação mais baixa dentre os traçados propostos, pode-se considerar como satisfatória.

O traçado 2, em comparação com os outros, é o que está inserido em áreas mais favoráveis para implantação de rodovias. A avaliação média é a mais alta entre os traçados propostos $(\mathrm{Av}-2=$ $9,19)$. Cerca de $81,2 \%$ de seu traçado, estão inseridos em áreas favoráveis para a implantação de rodovias, e apenas 5,2\% estão em áreas desfavoráveis ou impróprias.

O traçado 3, comparaativamente aos demais, está em situação intermediária. A avaliação média está entre a avaliação dos traçados 1 e $2(A v-3=9,04)$. Cerca de 81,4\% de seu traçado estão inseridos em áreas favoráveis para a implantação de rodovias (maior porcentagem que o traçado 2 ). No entanto $8,9 \%$ estão em áreas desfavoráveis ou impróprias.

Aliado à análise da avaliação média, não se pode deixar de considerar a verificação das zonas de variação de máximos. Essas zonas evidenciam a variação no campo de tensão de deformação pela mudança direcional do eixo de maior tensão $\left(\sigma_{1}\right)$, a qual se associa com regiões intensamente fraturadas, possibilitando mai-
Tabela 6-Resultados da tabulação cruzada nos traçados 1, 2 e 3.

\begin{tabular}{|c|c|c|c|c|c|c|c|}
\hline Traçado 1 & APAs & $\begin{array}{c}\text { Área } \\
\text { Urbana }\end{array}$ & Impróprio & Desfavorável & Regular & Favorável & Total \\
\hline pixels & 0 & 0 & 186 & 2.361 & 3.465 & 12.159 & 18.171 pixels \\
\hline$\%$ & 0 & 0 & 1,0 & 13,0 & 19,1 & 66,9 & $100 \%$ \\
\hline $\mathrm{km}$ & 0 & 0 & 0,375 & 5,975 & 9,33 & 34,28 & $50,0 \mathrm{~km}$ \\
\hline \multicolumn{8}{|l|}{ Traçado 2} \\
\hline pixels & 0 & 0 & 57 & 871 & 2.388 & 14.328 & 17.644 pixels \\
\hline$\%$ & 0 & 0 & 0,3 & 4,9 & 13,5 & 81,2 & $100 \%$ \\
\hline $\mathrm{km}$ & 0 & 0 & 0,175 & 2,675 & 6,5 & 42,575 & $52,0 \mathrm{~km}$ \\
\hline \multicolumn{8}{|l|}{ Traçado 3} \\
\hline pixels & 0 & 0 & 221 & 1.395 & 1.767 & 14.789 & 18.172 pixels \\
\hline$\%$ & 0 & 0 & 1,2 & 7,7 & 9,7 & 81,4 & $100 \%$ \\
\hline $\mathrm{km}$ & 0 & 0 & 0,38 & 3,38 & 5,33 & 43,55 & $52,6 \mathrm{~km}$ \\
\hline
\end{tabular}

Tabela 7 - Avaliações médias dos traçados 1, 2 e 3.

\begin{tabular}{|c|c|}
\hline Traçado & Avaliação Média \\
\hline Av-1 & 8,39 \\
\hline Av-2 & 9,19 \\
\hline Av-3 & 9,04 \\
\hline
\end{tabular}

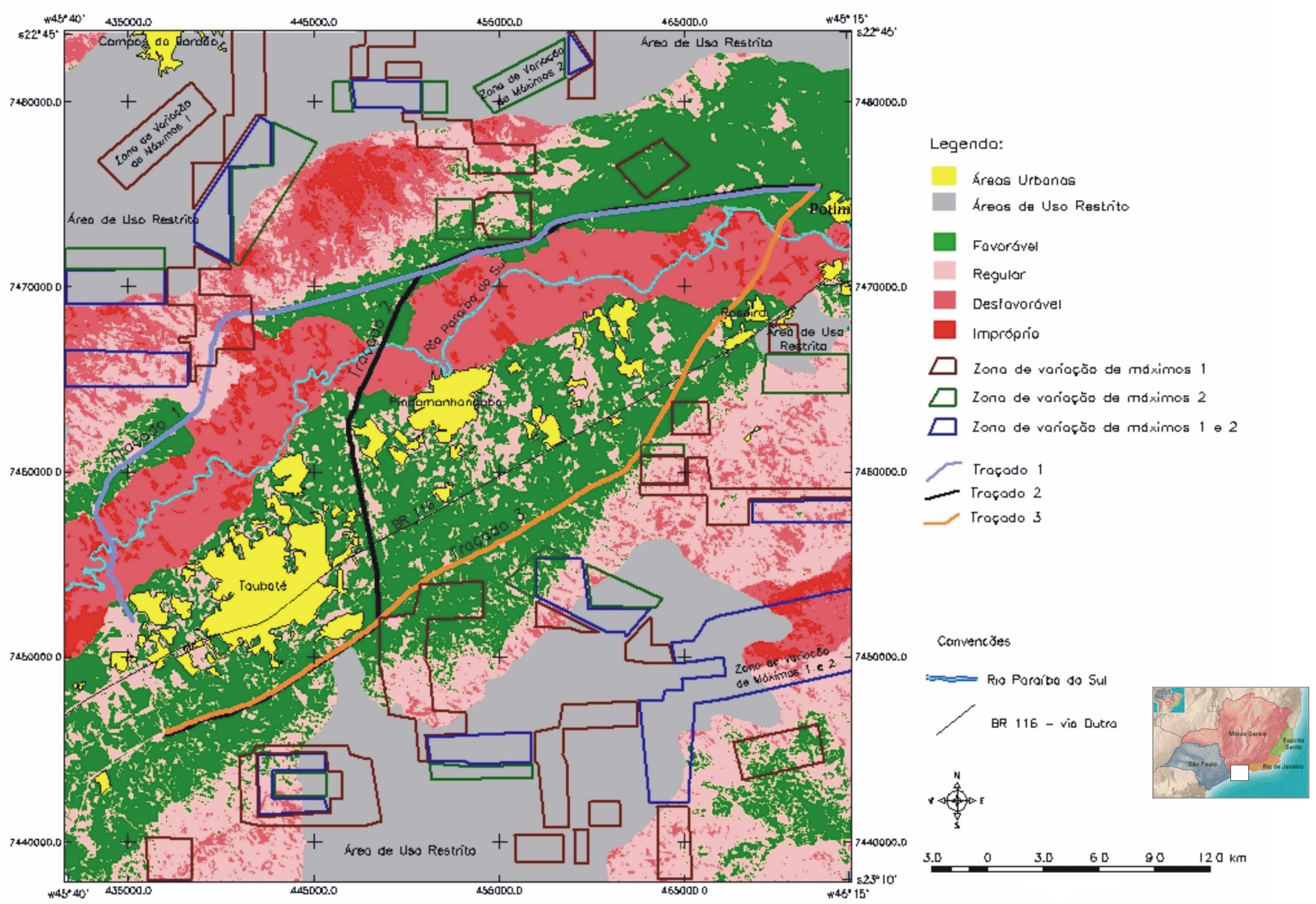

Figura 8-Carta de Aptidão Física, Sócio-Econômica e Ambiental para avaliar as áreas potenciais para a implantação do prolongamento da rodovia Carvalho Pinto. 
or percolação de fluídos. Como estas zonas são anomalias localizadas, não são passíveis de modelamento pela operação AHP. Assim, o traçado 1 é ainda mais impraticável, pois na região a norte de Tremembé este cruza uma zona de variação de máximos 1 .

É oportuno frisar que a Carta de Aptidão Física não tem a finalidade de dispor de traçados para o prolongamento da via Carvalho Pinto, mas propor uma sistemática que consistiu em analisar os fatores condicionantes geológicos e geotécnicos do meio físico, em conjunto com outros de interesse rodoviário (declividade, uso e cobertura da terra e áreas de uso restrito), para mapear a potencialidade da área à implantação de rodovias, e facilitar o trabalho dos planejadores de obras viárias.

CONSIDERAÇÕES FINAIS Os produtos da tecnologia de sensoriamento remoto mostraram-se altamente promissores para o estudo do zoneamento geoambiental em escala regional, relacionado com as informações obtidas com esses produtos de temas afins, principalmente de fisiografias, litologias, pedogeológicas, unidades e coberturas de alteração intempérica e de anomalias morfoestruturais.

A sistemática metodológica adotada mostrou-se bastante eficiente, com suas atividades interrelacionadas e dependentes de uma perfeita discriminação e definição das zonas fotogeológicas homogêneas. Isso foi possível pelo estudo integrado dos atributos espaciais interpretados em produtos de sensoriamento remoto orbital, por meio da análise do arranjo textural de elementos de relevo e drenagem.
A interrelação das atividades foi muito promissora, visto que os resultados intermediários obtidos nas diversas fases da sistemática foram integrados com razoável facilidade, tanto para a obtenção do mapa de unidades e coberturas de alteração intempérica, como do mapa de zonas e subzonas geoambientais da região do alto-médio rio Paraíba do Sul.

A delimitação e cartografia de unidades e coberturas de alteração intempérica com o uso de sensoriamento remoto orbital, como realizado na região do alto-médio rio Paraíba do Sul, constituiu-se em um fato inédito na região.

$\mathrm{O}$ zoneamento geoambiental do meio físico obtido com sensoriamento remoto orbital mostrou-se bastante adequado para os diversos planejadores que buscam subsídios técnicos para a definição e prioridades nos estudos de obras de engenharia, recursos hídricos, uso agrícola direcionado, planejamento territorial, proteção ambiental, dentre outras aplicações relacionadas com o meio físico.

No caso da carta de aptidão física para avaliar as áreas potenciais visando a implantação de obras viárias, as imagens de satélite mostraram-se como ferramentas de baixo custo relativo, rápida aquisição e processamento, com possibilidade de várias cenas e com diferentes datas para a mesma área. São fáceis e ágeis na sua manipulação em um ambiente SIG, além de ser uma grande fonte de informações do meio físico e do uso e cobertura da terra.

Agradecimentos Aos revisores da RBG pelas sugestões ao manuscrito.

\section{Referências}

Bonham-Carter G.F. 1994. Geographic information systems for geoscientists: modelling with GIS. Kidlington, Elsevier Science, 398p.

Caetano N.R. 2002. Utilização de sensoriamento remoto orbital e sistema de informação geográfica como subsidio a fase de anteprojeto de rodovias. Estudo de caso: extensão da rodovia Carvalho Pinto. INPE, DSR, São José dos Campos, SP, Dissertação de Mestrado, 91 p.

Caetano N.R., Mattos J.T. \& Ohara T. 2002. Sensoriamento remoto e sistema de informação geográfica como ferramentas no planejamento de rodovias. In: X Simpósio Latinoamericano de Percepción Remota, Cochabamba, Bolívia. Anais em CD-ROM. (Selper $\backslash a r t i c u l o s \backslash$ T095.pdf). $10 \mathrm{p}$.

Jiménez-Rueda J.R., Nunes E. \& Mattos J.T. 1993. Caracterização fisiográfica e morfoestrutural da folha São José de Mipibu - RN. Geociências, São Paulo, 12(2):481-491.

Jiménez-Rueda.J.R., Pessotti J.E.S. \& Mattos J.T. 1989. Uso de sensoriamento remoto no zoneamento agroecológico da região da serra do Mar no estado de São Paulo. In: Simpósio Latino-Americano de Percepción Remota, IV., San Carlos de Bariloche, Argentina. Anais. Tomo I, p.135-140.

Kurkdjian M.L.N.O., Valério Filho M., Veneziani P., Pereira M.N., Florenzano T.G., Anjos C.E., Ohara T., Donzeli P.L., Abdon M.M., Sausen T.M., Pinto S.A.F., Bertoldo M.A., Blanco J.G. Czordas S.M. 1992. Macrozoneamento da região do vale do Paraíba e litoral norte do estado de São Paulo. INPE, São José dos Campos, SP, 176p. (INPE 5381).
Ohara T. 1995. Zoneamento geoambiental da região do alto-médio Paraíba do Sul (SP) com sensoriamento remoto. IGCE, UNESP, Rio Claro, SP. Tese de Doutoramento em Geologia Regional, 235 p.

Ohara T., Jiménez-Rueda J.R. , Mattos J.T. 1997a. Análise da evolução pedogenética através de índices pedogeoquímicos de perfis de alteração intempérica nos planaltos do Paraitinga-Paraibuna e da Serra da Mantiqueira e no Vale do Paraíba (SP). In: Congresso Brasileiro de Ciência do Solo, XXVI., Rio de Janeiro, Anais em CD-ROM.

Ohara T., Mattos J.T., Jiménez-Rueda J.R. 1997b. Utilização da tecnologia de sensoriamento remoto no estudo geoambiental do meio físico em região com fisiografias de planaltos e planícies. In: Simpósio Brasileiro de Geografia Física Aplicada, VII. / Fórum Latino-Americano de Geografia Física Aplicada, I., Curitiba, Anais em CD-ROM.

Saaty T.L. 1992. Multicriteria Decision Making - The Analytical Hierarchy Process. Pittsburg, RWS Publications.

USDA. 1975. Soil Taxonomy: a basic system of soil classification of making and interpreting soil surveys. USDA. handbook, $436.754 \mathrm{p}$.

Vedovello R. 2000 Zoneamentos geotécnicos aplicados à gestão ambiental, a partir de unidades básicas de compartimentação-UBCs. IGCE, UNESP, Rio Claro, SP. 154p. Tese de Doutoramento em Geociências e Meio Ambiente, 154 p.

Manuscrito SR-23

Recebido em 17 de novembro de 2002 Revisão dos autores em 03 de abril de 2003 Revisão aceita em 05 de maio de 2003 